\title{
Seismic imaging of a thermohaline staircase in the western tropical North Atlantic
}

\author{
I. Fer ${ }^{1}$, P. Nandi ${ }^{2}$, W. S. Holbrook ${ }^{3}$, R. W. Schmitt ${ }^{4}$, and P. Páramo ${ }^{5}$ \\ ${ }^{1}$ Geophysical Institute, University of Bergen, Allégaten 70, 5007, Bergen, Norway \\ ${ }^{2}$ BP America, Inc., 501 Westlake Park Blvd, Houston, TX 77079, USA \\ ${ }^{3}$ Dept. of Geology and Geophysics, University of Wyoming, Laramie, WY 82071, USA \\ ${ }^{4}$ Dept. of Physical Oceanography, Woods Hole Oceanographic Institution, Woods Hole, MA 02543, USA \\ ${ }^{5}$ BP Exploration, Bldg H, Chertsey Road, Sunbury-on-Thames, TW16 7LN, UK
}

Received: 8 February 2010 - Published in Ocean Sci. Discuss.: 24 February 2010

Revised: 18 May 2010 - Accepted: 22 June 2010 - Published: 2 July 2010

\begin{abstract}
Multichannel seismic data acquired in the Lesser Antilles in the western tropical North Atlantic indicate that the seismic reflection method has imaged an oceanic thermohaline staircase. Synthetic acoustic modeling using measured density and sound speed profiles corroborates inferences from the seismic data. In a small portion of the seismic image, laterally coherent, uniform layers are present at depths ranging from $550-700 \mathrm{~m}$ and have a separation of $\sim 20 \mathrm{~m}$, with thicknesses increasing with depth. The reflection coefficient, a measure of the acoustic impedance contrasts across these reflective interfaces, is one order of magnitude greater than background noise. Hydrography sampled in previous surveys suggests that the layers are a permanent feature of the region. Spectral analysis of layer horizons in the thermohaline staircase indicates that internal wave activity is anomalously low, suggesting weak internal waveinduced turbulence. Results from two independent measurements, the application of a finescale parameterization to observed high-resolution velocity profiles and direct measurements of turbulent dissipation rate, confirm these low levels of turbulence. The lack of internal wave-induced turbulence may allow for the maintenance of the staircase or may be due to suppression by the double-diffusive convection within the staircase. Our observations show the potential for seismic oceanography to contribute to an improved understanding of occurrence rates and the geographical distribution of thermohaline staircases, and should thereby improve estimates of vertical mixing rates ascribable to salt fingering in the global ocean.
\end{abstract}

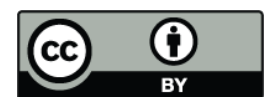

Correspondence to: I. Fer (ilker.fer@gfi.uib.no)

\section{Introduction}

Thermohaline staircases are regular, well-defined step-like variations in vertical profiles of temperature and salinity that can occur when vertical temperature and salinity gradients share the same sign (Kelley, 1984). In the ocean, they are the result of double diffusion driven by the difference in molecular diffusivities for heat and salt (Turner, 1973). In a statically stable setting, density-compensating profiles of temperature and salinity can lead to double-diffusive convection for a top-heavy temperature profile (e.g., typical above the subsurface warm Atlantic Water in the Arctic Ocean, Kelley et al., 2003), and to salt fingers for a top-heavy salinity profile (Stern, 1960; Schmitt, 2003). Double diffusion is shown to influence the efficiency of diapycnal mixing (across density surfaces), for both diffusive convection (Sundfjord et al., 2007) and salt fingering (St. Laurent and Schmitt, 1999) regimes. Here, we discuss the situation where both salinity and temperature decrease with depth, i.e. when a warmer salty body of water overlies a colder fresher body typical for example in the subtropical ocean, leaving conditions favorable for the development of salt finger staircases. Finger instabilities cause small-scale convection cells that can induce significant vertical fluxes at high-gradient interfaces between well-mixed layers with contrasting temperature and salinity.

Studies have suggested that salt fingering can greatly affect the vertical transport of heat and salt in the thermocline and play a significant role in maintaining the global thermohaline stratification (Schmitt et al., 1987, 2005). Salt fingering may play a role in the tightness and shape of the mean temperature-salinity relation in the central waters of subtropical gyres (Schmitt, 1981, 1990). Numerical modeling by Zhang and Schmitt (2000) shows that the stability

Published by Copernicus Publications on behalf of the European Geosciences Union. 
of thermohaline circulation is highly dependent on a critical freshwater flux value, which is reduced in the presence of salt fingering. Results of the North Atlantic Tracer Release Experiment, conducted near the Canary Islands, indicated an enhancement of saline diffusivity over thermal diffusivity of more than $60 \%$ by salt fingering. The mixing rates inferred from tracer dissipation measurements were better explained with the presence of salt fingering (St. Laurent and Schmitt, 1999). More recently, the Salt Finger Tracer Release Experiment (SFTRE) revealed that vertical mixing was greatly enhanced by the presence of a salt fingering thermohaline staircase with a factor of two enhancement of the haline mixing rate over the thermal mixing rate (Schmitt et al., 2005).

The importance of salt finger processes to ocean structure and circulation emphasizes the need to understand their temporal and spatial occurrence in the environment. The application of models, tracer experiments, and laboratory studies to the open ocean is still poorly understood, and further insights can be gained from improving observational capabilities. Our study utilizes geophysical techniques to observe physical processes over a large spatial area in the ocean, which has the potential to add significantly to the body of staircase observations available to the oceanographic community.

New research in marine geophysics has demonstrated the ability of the multichannel seismic reflection method, sensitive to abrupt vertical changes in sound speed and density, to provide images of physical oceanic processes with exceptional horizontal resolution. Holbrook et al. (2003) first related water-column reflections to oceanic finestructure in a front between the Labrador Current and the North Atlantic Current. A descriptive introduction on the seismic reflection method with a focus on water column interpretations can be found in Fer and Holbrook (2008), Ruddick et al. (2009), and Pinheiro et al. (2010). Temperature-salinity contrasts in the water column result in small changes in sound speed and appear in seismic images as distinct reflection layers revealing exceptional detail between $10-100 \mathrm{~m}$ horizontal resolution throughout the water column. Spectacular images of thermohaline finestructure in the ocean include features such as intrusions (Holbrook et al., 2003), fronts (Holbrook et al., 2003; Nakamura et al., 2006), water mass boundaries (Nandi et al., 2004), internal waves (Holbrook and Fer, 2005; Krahmann et al., 2008), internal tide characteristics (Holbrook et al., 2009) and mesoscale eddies (Biescas et al., 2008; Pinheiro et al., 2010). A clear relationship has been established between recorded seismic reflectance and the presence of thermohaline finestructure (Nandi et al., 2004). A detailed derivation in Ruddick et al. (2009) shows that seismic imaging is approximately (but not entirely) a smoothed vertical derivative of temperature on the scale of the acoustic wavelet (order of $10 \mathrm{~m}$ ). On average, $80 \%$ of the reflectivity is due to temperature contrasts (Sallarès et al., 2009), whereas the typical contribution of salinity anomalies to reflectivity is about 20\% (Sallarès et al., 2009; Ruddick et al., 2009) (see Sect. 2.2 for the definition of reflectivity). The latter does not affect the patterns on the final seismic image, since the vertical gradients of salinity and temperature are tightly correlated.

Here, we present a seismic transect from an area previously shown to be prone to salt-finger staircase development, in the western tropical North Atlantic near the Lesser Antilles (Schmitt et al., 1987). Seismic data are supplemented by oceanographic measurements of hydrography, currents and microstructure, and synthetic modelling. Data and methodology are presented in Sect. 2. In Sect. 3.2, we demonstrate the enhanced reflectivity associated with the thermohaline staircase. By modeling a synthetic seismic response to physical parameters, we show that seismic reflections can provide a high-resolution image of a thermohaline staircase (Sect. 3.3). Assuming that the reflectors oscillate with isopycnals, we infer the internal wave field from spectral analysis of seismic data, to show weak internal wave activity in the staircase and provide support from oceanographic measurements (Sect. 3.5). Subsequently, we put a constraint on the longevity of the staircase observed in an earlier hydrography survey (Sect. 3.4). Results from independent sampling and analysis are self-consistent and provide evidence that seismic oceanography is capable of detecting the structure and distribution of thermohaline staircases. The seismic reflection methodology may be used to analyze processes that affect thermohaline finestructure and provides new observational insights into physical oceanography.

\section{Experimental methods}

\subsection{Data}

The seismic data were acquired on board the R/V "Maurice Ewing" from 15 March through 6 April 1998 (Bangs, 1998). An air-gun array composed of 20 air-guns with a combined volume of 8420 cubic inches $(\sim 1381)$ generated acoustic energy with shot intervals of $50 \mathrm{~m}$. Reflected energy was recorded on a $4.1-\mathrm{km}$-long streamer containing 164 hydrophone groups, or traces, at $25 \mathrm{~m}$ spacing, resulting in horizontal subsurface sampling at each midpoint between the shot location and hydrophone group of $12.5 \mathrm{~m}$. Data processing follows standard routines including muting of the direct arrival. Data were digitized at 250 samples per second, stacked, corrected for spherical divergence and filtered through a minimum-phase trapezoidal band pass filter. Lastly, data were input into a 2-D Kirchhoff migration, an algorithm chosen for simplicity and ease of calculation in time rather than depth, as no highly varying lateral velocity variations were expected to be encountered in the water column. Ruddick et al. (2009) give an introduction to basic principles regarding the vertical and horizontal resolution associated with seismic sampling, and describe migration and its consequences on the horizontal resolution. The horizontal resolution is expected to be better than the Fresnel zone radius 

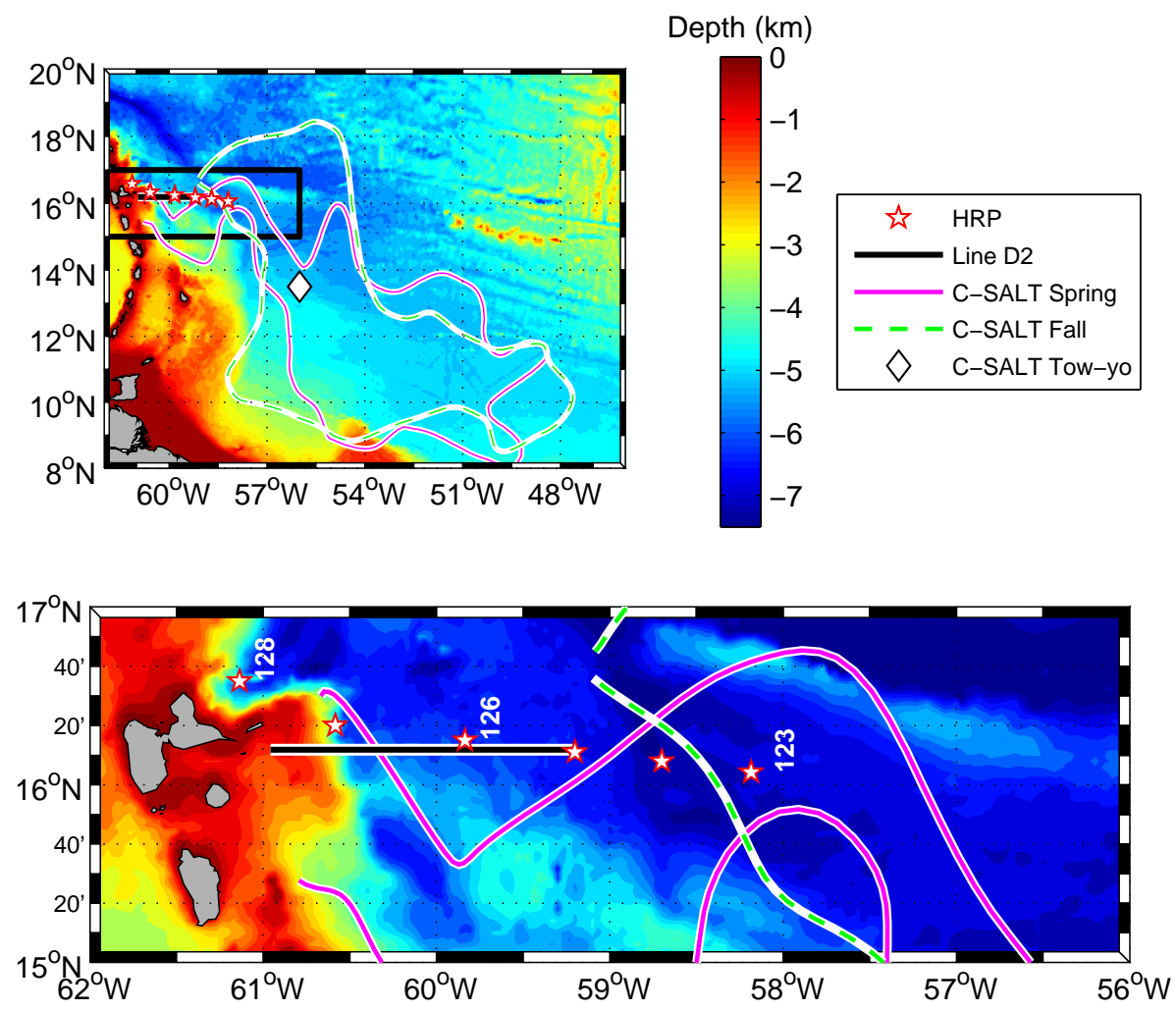

Fig. 1. Bathymetric map of the study area near the Lesser Antilles in the Caribbean Sea. Lower panel is a blow-up of the study region marked by the rectangle in the upper panel. Line D2 (black) is the transect of the 1998 seismic reflection survey. The stations where the high-resolution profiler (HRP) was deployed in 2001 are marked by red stars (dives 123 to 128). Dive 123 (easternmost) is used in the synthetic modeling (Sect. 2.3). Dive 125, at the eastern end of Line D2, is used to constrain the longevity of the layers. The spatial extent of strong staircases identified during the 1985 C-SALT experiment is shown for the spring (magenta) and fall (dashed green) surveys together with the C-SALT tow-yo location (diamond) (Schmitt et al., 1987).

$R=(\lambda h / 2)^{1 / 2}$ where $h$ is the reflection depth and $\lambda=c / f_{0}$ is the wavelength of sound, $c$ is the sound velocity and $f_{0}$ is the wavelet peak frequency (Ruddick et al., 2009; Sheriff and Geldart, 1995). Between 550 and $850 \mathrm{~m}$, covering the depth range of the thermohaline staircase identified in Sect. 3.1, $R$ varies between 110 and $150 \mathrm{~m}$. Migration partially increases the horizontal resolution which lies between $R$ and the hydrophone group spacing.

In this study, we present results from Line D2, which was acquired from west to east just outside the Caribbean Sea (Fig. 1). Close to the seismic line, full-depth profiles of conductivity, temperature, depth (CTD), and currents were collected using the High Resolution Profiler (HRP, Schmitt et al., 1988), during the Salt Finger Tracer Release Experiment - Part 2 (SFTRE-2) cruise on board the R/V "Seward Johnson" between 29 October and 4 December 2001 (Fig. 1, stars). The physical oceanography sampling is thus more than three years after the seismic transect. HRP is a freefall profiler sampling finestructure (CTD and horizontal current) at $10 \mathrm{~Hz}$ and microstructure (temperature, conductivity and shear) at $200 \mathrm{~Hz}$, at a nominal descent rate of $0.6 \mathrm{~m} \mathrm{~s}^{-1}$. Data processing follows standard routines and can be found, for example, in Polzin and Montgomery (1998). Here, $0.5 \mathrm{~m}$ vertical resolution profiles of finescale CTD and horizontal velocity, and dissipation rate of turbulent kinetic energy are used. The location of Line D2 and the HRP stations is within the limits of the aircraft-deployed expendable bathythermograph survey of the Caribbean-Sheets And Layers Transects (C-SALT) experiment (Schmitt et al., 1987), and lies approximately $220 \mathrm{~km}$ north of the C-SALT CTD tow-yo section. The C-SALT survey was conducted in 1985. In order to calculate the reflection coefficients in a well-defined strong thermohaline staircase, we make use of a C-SALT CTD tow-yo profile (Fig. 7a).

The seismic reflection data from the area at the depths of the staircase indicate a dominant return frequency of about $30 \mathrm{~Hz}$ (or a wavelength of approximately $50 \mathrm{~m}$ ), with a spectral content of 5 to $100 \mathrm{~Hz}$. A CTD profile from HRP indicates an average sound speed of $1491 \mathrm{~m} \mathrm{~s}^{-1}$ between 550 and $850 \mathrm{~m}$ (covering the depth range of the thermohaline staircase identified in Sect. 3.1). For a single isolated rock-layer interface in a homogeneous background, the vertical resolution is $1 / 8$ th of the dominant wavelength, in this case about $6 \mathrm{~m}$ (Widess, 1973). The vertical resolution is expected to 
be coarser due to presence of a series of steps and smoother acoustic impedance contrasts in water compared to rock layer interfaces. Thus, the seismic reflection method should be able to distinguish layers as thin as $10 \mathrm{~m}$.

\subsection{Reflectivity}

Acoustic impedance, $I$, is the product of density $\rho$, and sound speed, $c$; both typically vary with depth in the ocean: $I(z)=\rho(z) c(z)$. The reflection coefficient or reflectivity, $R_{i}$, is a measure of the impedance contrast at boundaries. See Ruddick et al. (2009) and Sallarès et al. (2009) for a detailed discussion on the relative contribution of temperature and salinity on reflectivity in seawater. In Sect. 3.2 we contrast reflectivity derived from hydrographic observations and seismic data. For the latter, reflection coefficients were derived from a time-migrated seismic profile using a constant sound speed of $1491 \mathrm{~m} \mathrm{~s}^{-1}$. The amplitude of the sea floor $\left(A_{\mathrm{sf}}\right)$ and its first multiple ( $\left.A_{\text {mult }}\right)$ were used to normalize the amplitudes of the reflections in the staircase $\left(A_{i}\right)$ using $R_{i}=A_{i} / A_{0}$, where $A_{0}=-\left(A_{\mathrm{sf}}^{2}\right) / A_{\text {mult }}$ (Warner, 1990). Diffractions at the sea floor underneath the staircase reported incorrect amplitudes and travel times for the reflectors, necessitating the inclusion of time-migration as an additional processing step. After migration, the sea floor was moved into a more consistent position with respect to its location on adjacent common depth profiles, and sea floor amplitudes had less interference from other reflectors. The choice of constant sound speed, however, leads to a reduction in signalto-noise ratio and can mask features revealed by using in-situ sound speed profiles (Fortin and Holbrook, 2009).

From these data, reflection coefficients were calculated using CTD tow-yo data collected during the C-SALT survey in 1985. For continuous profiles of $\rho(z)$ and $c(z)$, the water column can be approximated as a sequence of layers allowing the calculation of the reflectivity coefficient between two adjacent layers $i$ and $i+1$ as $R_{i}=\left(I_{i}-I_{i+1}\right) /\left(I_{i}+I_{i+1}\right)$. Consistent with the seismic profiling vertical resolution of $10 \mathrm{~m}$ (a conservative estimate, see Sect. 2.1), a vertical quantization interval of $10 \mathrm{~m}$ was applied.

\subsection{Synthetic modeling}

Using a CTD profile from HRP, 2-D acoustic synthetic modeling of a shot gather using a simulated air gun size, shot and receiver spacing of the actual seismic survey is conducted to characterize the pattern of reflectivity expected from finestructure in a thermohaline staircase. Density and sound speed profiles between 10 and $1474 \mathrm{~m}$ depth were averaged over $4 \mathrm{~m}$ intervals to create a 364 layer representation of the water column. The measured sound speed profile is used to convert from time to depth. The final model used 164 receivers and a streamer length of $4.1 \mathrm{~km}$ to match the seismic data sampling (Sect. 2.1).

\subsection{Spectral analysis}

Vertical displacements of reflections from oceanic finestructure recorded in the Norwegian Sea were shown to be representative of the internal wave field (Holbrook and Fer, 2005). In order to infer the internal wave energy level from spectral analysis, we digitized representative reflection horizons at $12.5 \mathrm{~m}$ horizontal resolution, and categorized them into groups based on their proximity to the staircase. Reflection depths were linearly detrended to produce vertical displacements $(\zeta)$ from the mean reflection position. Horizontal wavenumber spectra $\left(\phi_{\zeta}\left(k_{x}\right)\right)$ were then calculated with a Welch Fourier transform using 128 point long $(1600 \mathrm{~m})$ Hanning windows. The spectral analysis assumes that the reflection horizons oscillate with the isopycnals, which can be erroneous in the presence of density-compensating thermohaline staircase and intrusions. Following Klymak and Moum (2007) we present the spectra for the horizontal gradient of vertical displacements, i.e. slope spectra, $\phi_{\zeta_{x}}=$ $\left(2 \pi k_{x}\right)^{2} \phi_{\zeta}$. The slope spectra is suitable for seismic reflection surfaces which do not necessarily follow isopycnals on all scales and also allows an easier visual identification of internal wave and turbulence sub-range. The resulting spectra were scaled by $N / N_{0}$ where $N$ is the mean buoyancy frequency within the depth span of the selected reflection and $N_{0}=5.2 \times 10^{-3} \mathrm{~s}^{-1}$. The buoyancy frequency is approximated from the potential density anomaly $\sigma_{\theta}$ (referenced to zero surface pressure) as $N=\left[-g \rho^{-1} \partial \sigma_{\theta} / \partial z\right]^{1 / 2}$ where $z$ is depth, $g$ is gravitational acceleration and $\rho$ is the reference seawater density. A survey-averaged $N$ profile is calculated over $30 \mathrm{~m}$ vertical scale using the CTD profiles from HRP dives shown in Fig. 1.

\section{Results and discussion}

\subsection{Thermohaline staircase}

In the spring of 1998, the seismic Line D2 in the Lesser Antilles (Fig. 1) captured patterns suggestive of a salt finger thermohaline staircase (Fig. 2). At least $4 \mathrm{~km}$ in length, the staircase is composed of four thick, regular, nearly horizontal reflectors with a vertical spacing of about $20 \mathrm{~m}$, consistent with the structure expected from high-gradient interfaces separating mixed layers. Layer thicknesses, measured as peak to peak distance between adjacent wavelets vary between $19 \mathrm{~m}$ and $25 \mathrm{~m}$. This structure located about $190 \mathrm{~km}$ east of Guadeloupe visible at depths between 550 and $700 \mathrm{~m}$, is distinguished by its clarity, strong amplitude, lack of modulations and slope. The stack of regular, uniformly-spaced quasi-horizontal reflections form bands which are not present elsewhere in the section. Here, it is suggested to be representative of the thermohaline staircase. 


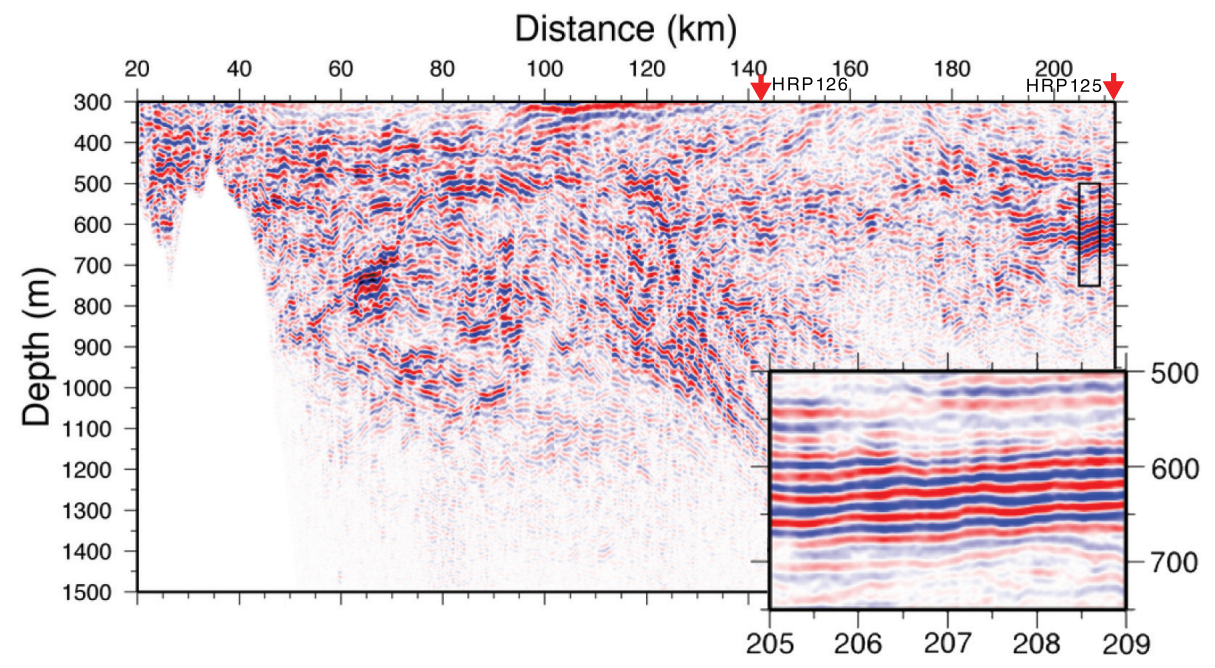

Fig. 2. Vertically exaggerated seismic image of Line D2, collected from west to east across the Caribbean Sea with the shelf of Guadeloupe on the left (masked white). The thermohaline staircase is the high amplitude reflective package (inset) visible from about 190-212 km at depths between 550 and $700 \mathrm{~m}$. These regular, uniformly spaced, banded layers are unique to this part of the section. Relative positions of the HRP dives 125 and 126, collected 3 years after the seismic survey, and approximately 5.8 and $1.6 \mathrm{~km}$ north of the seismic line respectively, are marked on top.

Decades of data collected in the western tropical North Atlantic show that the conditions favorable for the formation of thermohaline staircases are present permanently in this area (Schmitt, 2003). The representative hydrography inferred from HRP dive 125 is shown in Fig. 3. The water column is composed of Subtropical Underwater, a high salinity water mass that overlies Antarctic Intermediate Water, characterized by a salinity minimum. Together, these bodies present a decreasing profile of salinity and temperature with depth, necessary for salt-finger staircase development. Taken within the C-SALT site, seismic Line D2 crosses an area with strong staircases during the spring of 1985 , and lies at the border between strong and weak staircases in the Fall of 1985 (Fig. 1). The existence of a thermohaline staircase is thus quite likely in this region. Thermohaline staircases have been observed many times in the area east of the Caribbean Sea since the early days of continuous electronic profiling, including salinity-temperature-depth profiles from 1967 (Mazeika, 1974).

Because turbulent mixing may disrupt the regular structure of thermohaline staircases, they are most apparent where interactions from internal waves, rough topography, boundary forcing and other processes affecting flow stability do not significantly affect their characteristic step-like signature. The staircase imaged in the seismic line extends about $22 \mathrm{~km}$ eastward from its position in Fig. 2 at about $190 \mathrm{~km}$ to about $212 \mathrm{~km}$, in the depth range of 550-700 m. However, reflective horizons become less regular and have lower amplitudes westward of about $200 \mathrm{~km}$ with the deepest high-gradient layer disappearing altogether in places.

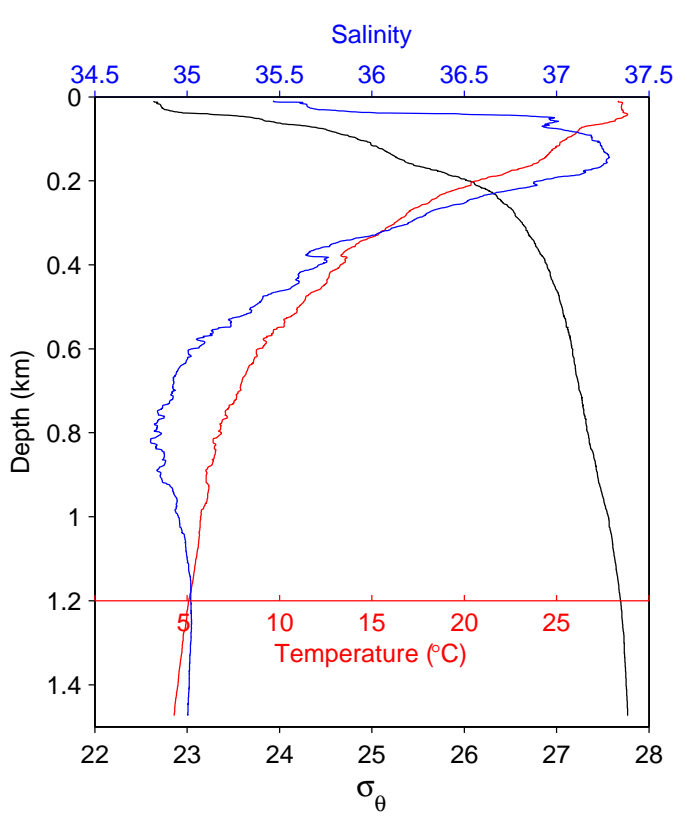

Fig. 3. Temperature (red), salinity (blue) and potential density anomaly ( $\sigma_{\theta}$, referenced to zero pressure, black) measured by HRP dive 125 near the eastern end of the seismic profile (Fig. 1). Water masses characteristic of this region are the Caribbean Surface Water with a salinity less than 35.5 at depths less than $50 \mathrm{~m}$, Subtropical Underwater at depths 50-200 $\mathrm{m}$ and a salinity maximum exceeding 37, and Antarctic Intermediate Water at depths 600-1000 m and a salinity minimum of around 34.7. 

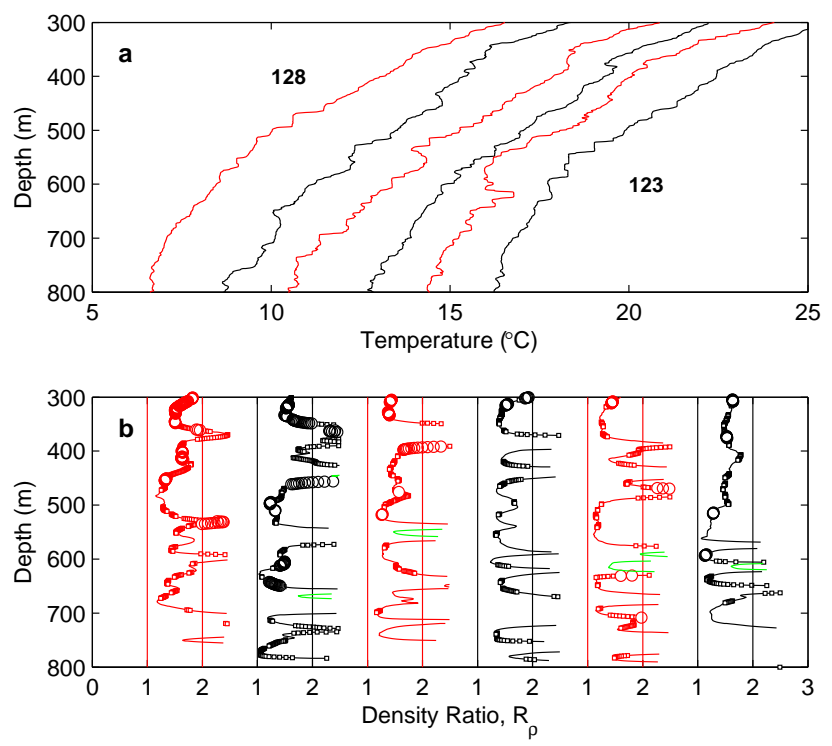

Fig. 4. Profiles of a) temperature and b) density ratio, $R_{\rho}$ inferred from the HRP dives deployed in 2001. Dive 123 indicates data upon a synthetic seismic study was based. The temperature scale is correct for the leftmost CTD. Each subsequent profile is offset by $2{ }^{\circ} \mathrm{C}$, shown in alternating red and black color. Density ratio profiles are offset and colored accordingly with $R_{\rho}=1$ and 2 indicated by vertical lines. $R_{\rho}>2.5$ are masked for clarity. The portions favoring diffusive-layer convection $0<R_{\rho}<1$ are highlighted using $1 / R_{\rho}$ (green, shown in the range $1<1 / R_{\rho}<2.5$ ). The size of the circles are scaled according to the magnitude of $10-\mathrm{m}$ shear $\left(<1 \times 10^{-3} \mathrm{~s}^{-1}\right.$, no marker; $(1-3) \times 10^{-3} \mathrm{~s}^{-1} ;(3-6) \times 10^{-3} \mathrm{~s}^{-1}$; and $>6 \times 10^{-3} \mathrm{~s}^{-1}$, large marker)

The strength of the vertical salinity gradient, $S_{z}$, relative to the temperature gradient, $T_{z}$, can be expressed in terms of the density ratio, $R_{\rho}=\alpha T_{z} / \beta S_{z}$, where $\alpha$ and $\beta$ are the thermal expansion and haline contraction coefficients. We calculate $R_{\rho}$ from 0.5 -m resolution CTD profiles after estimating the gradients as the slope of linear fits to temperature and salinity against depth in $30 \mathrm{~m}$ moving segments. Double diffusion due to salt-fingering is strong for density ratios between 1 and 2 and increases as $R_{\rho}$ approaches unity (Schmitt, 1981). Strong staircases with well-defined layers and interfaces are found where the density ratio is less than 1.7, and the finestructure becomes irregular for $R_{\rho}$ near 2. Profiles of temperature and $R_{\rho}$ are shown in Fig. 4 for the HRP dives. Density ratios are low, approaching unity, for short segments of the profiles, most continuously in dive 123 , where relatively well-defined steps are observed. The temperature profiles also show intrusions susceptible to diffusive-layering convection. For $T$ and $S$ increasing downward strongest diffusive layering is expected for $1<1 / R_{\rho}<3$ (marked green in Fig. 4b). Although the density ratio favors staircase development for all profiles, strong velocity (Fig. 5) and shear (Fig. 4b) disrupt the vertical structure. The weak velocity

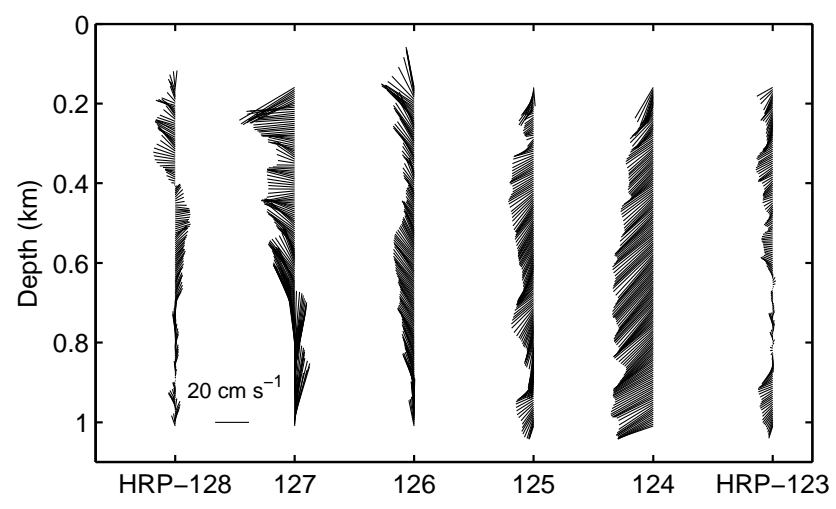

Fig. 5. Profiles of horizontal velocity for HRP dives 123 to 128 shown between $160-1010 \mathrm{~m}$. Velocity vectors from $15-\mathrm{m}$ smoothed profiles are shown at every $5 \mathrm{~m}$ (i.e., every 10 th data point of $0.5 \mathrm{~m}$ vertically sampled profiles).
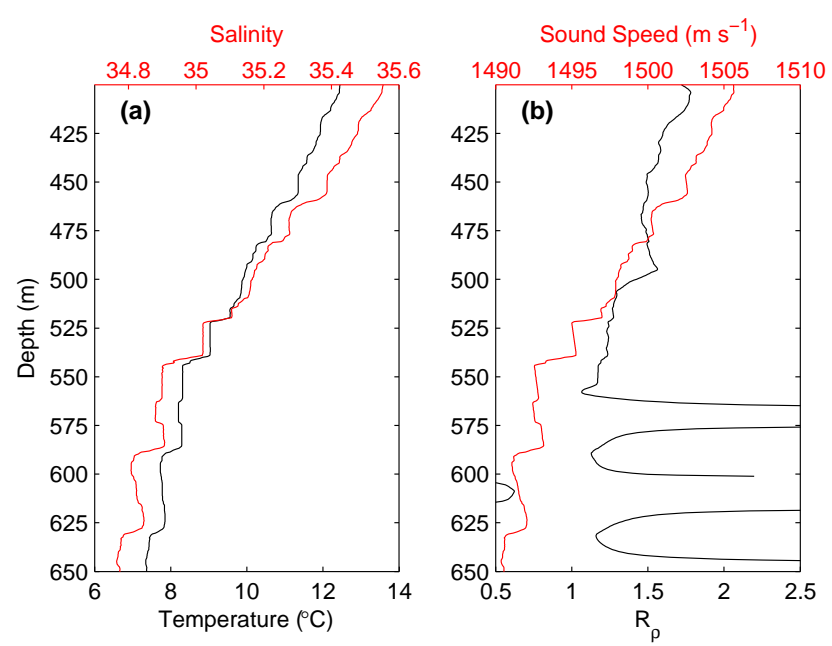

Fig. 6. Profiles of (a) temperature and salinity and (b) density ratio, $R_{\rho}$ and sound speed in the staircase (HRP dive 123). Sound speed and in-situ density profiles from this dive are used for the synthetic analysis.

and shear recorded in dive 123 allows for the presence of a staircase where $R_{\rho}<1.5$. Detailed profiles of temperature and salinity, sound speed and $R_{\rho}$ inferred from this dive are shown in Fig. 6, in the depth range between 400 and $650 \mathrm{~m}$. Observed temperature and salinity finestructure indicates three well-defined high-gradient steps separating four layers at depths between 520 and $630 \mathrm{~m}$ (Fig. 6). Layer thickness increases with depth from about 16 to $35 \mathrm{~m}$. Changes in density are small (not shown) because salinity and temperature largely compensate for each other, but abrupt variations in sound speed are large and occur over depth scales similar to those recorded in the temperature finestructure. 

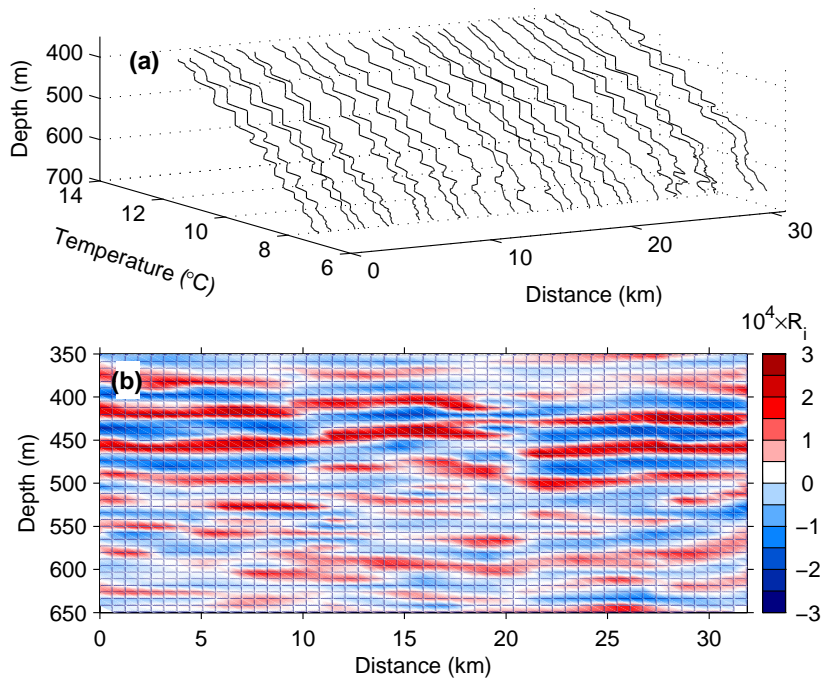

Fig. 7. (a) Three-dimensional view of CTD tow-yo temperature profiles collected during C-SALT at a strong, well-defined thermohaline staircase (Schmitt et al., 1987). Distance is inferred from the cumulative great-circle distance between the position at the start of each subsequent cast. (b) Reflection coefficients calculated from the C-SALT CTD tow-yo shown in (a). Peaks in reflection coefficient correspond to sharp changes in sound speed.

\subsection{Reflection coefficients}

How does the reflectivity change through a thermohaline staircase? Although the HRP dive 123 shows a staircase, it is somewhat irregular and weak. We therefore use profiles from a C-SALT tow-yo survey to exemplify the reflectivity signature in a staircase (Schmitt et al., 1987). Repeat temperature profiles reveal the staircase where $R_{\rho} \sim 1.6$, between 300 and $600 \mathrm{~m}$ with 5- to 30 -m-thick mixed layers separated by 1 - to $10-\mathrm{m}$-thick high-gradient interfaces (Fig 7a). The reflection coefficient profiles calculated here, using the CTD profiles from C-SALT, show layers corresponding to sharp changes in sound speed from layers in the step-like structure (Fig. 7b). We next calculate the reflection coefficients from the seismic Line D2, along a 4-km section centered at the structure resembling a staircase (inset in Fig. 1). In the section of the seismic survey centered on the staircase, reflection coefficients show high values with respect to background noise that are laterally coherent throughout the profile (Fig. 8). Absolute values calculated from the seismic data are slightly larger than those from the C-SALT CTD, which may be attributed to errors from noisy data and constructive interference of neighboring high amplitude wavelets. We conclude, however, the reflectivity pattern inferred from the seismic data set is consistent with that expected from a staircase and is indicative of the strength of temperature and salinity contrasts between mixed layers.

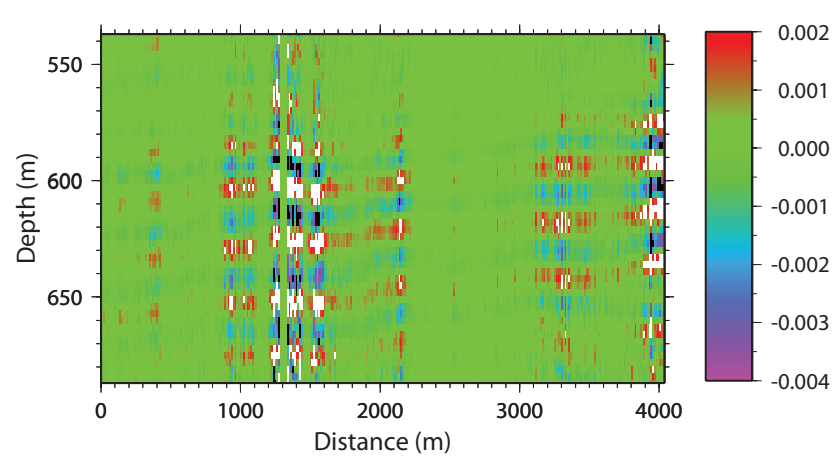

Fig. 8. Reflection coefficients calculated from a section of a $1 \mathrm{~km}$ near-offset time-migrated seismic stack, centered on the thermohaline staircase. Values at the high-gradient layers are larger than background noise and show a regular, lateral coherence throughout the profile. High values at 1400 and $4000 \mathrm{~m}$ (masked white) correspond to errors caused by a diffraction in the sea floor, only partially corrected by the migration, and extremely low sea floor and multiple amplitudes respectively.

\subsection{Synthetic analysis}

We can estimate the seismic reflection signature expected from the HRP dive 123 staircase by conducting synthetic seismic modeling (Sect. 2.3). Synthetic seismic traces created from density and sound speed profile from dive 123 (Fig. 9) show several hyperbolic reflections corresponding to vertical contrasts in sound speed. Shortly after a highamplitude linear direct arrival, reflections become visible at a depth of about $200 \mathrm{~m}$. Staircase reflections are the first strong packet of reflections to arrive after the direct arrival between 500 and $640 \mathrm{~m}$, which match the depths with high gradients in the sound velocity profile. The unique step-like banded appearance is seen in both the synthetic and the seismic data (compare insets in Figs. 2 and 9). Reflections with high amplitudes relative to their surroundings are laterally coherent, continuous and closely spaced, and resemble the observed staircase structure in Line D2, which lies $\sim 110 \mathrm{~km}$ to the west of the station location (Fig. 1). Because the synthetic seismic transect shows all the layers at the correct depths, we conclude that the seismic reflection method is capable of imaging the variations in finestructure that characterize a thermohaline staircase.

\subsection{Longevity}

Though strong staircases in the area have been observed since the advent of continuously profiling instruments in the late 1960's, the staircases are constantly advected and modified by eddies and internal waves. The longevity of the individual layers has yet to be constrained. Schmitt et al. (1987) observed in their moored time series that four strong layers retained their identity for the entire eight months between the two C-SALT surveys. This suggests a minimum lifetime 


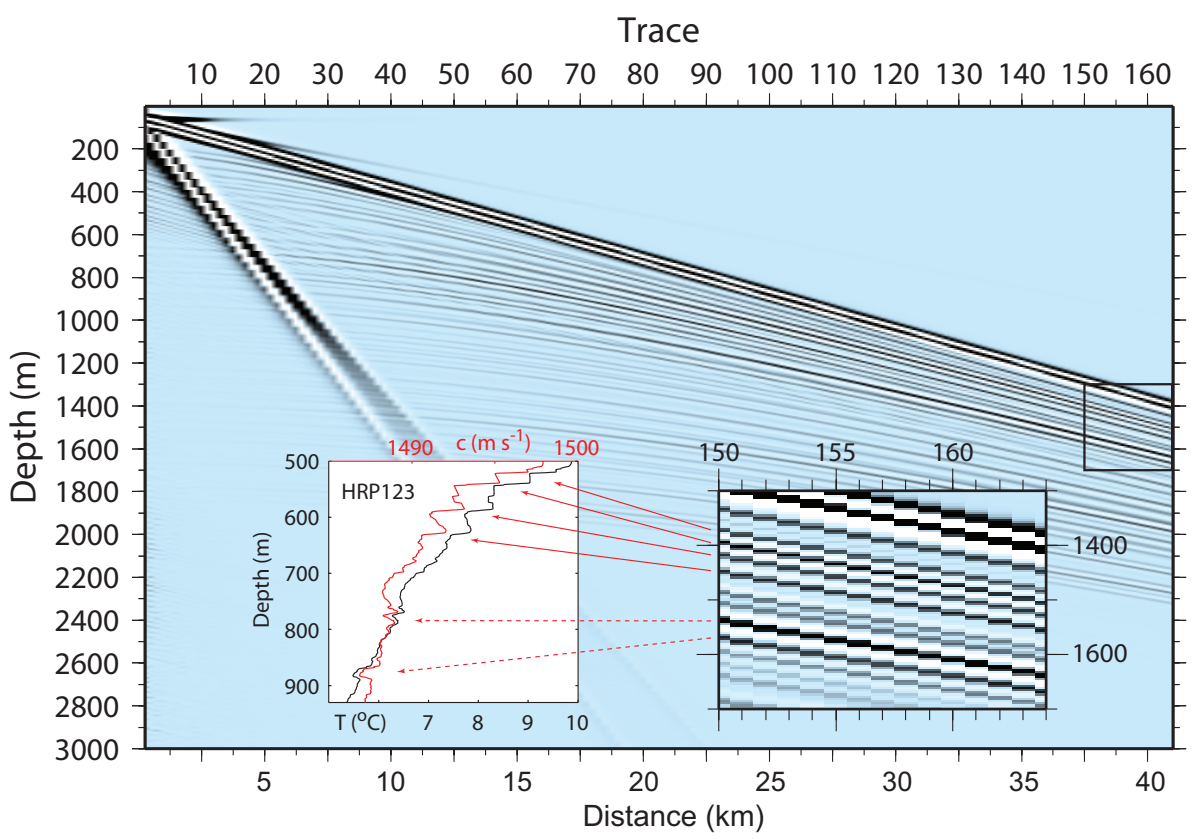

Fig. 9. Unstacked synthetic seismic shot gather using the CTD profile from HRP dive 123 east of Line D2 (Fig. 1). The direct arrival appears as large amplitude linear reflections starting at the sea surface. The airwave appears as the large linear event traveling at low velocity. Reflections from synthetic sound velocity and density structure calculated from the CTD are seen as hyperbolic horizons starting at about $200 \mathrm{~m}$ at trace 1, at zero offset, which occurs directly below the source. Reflections from further offsets follow a hyperbolic moveout with respect to the zero offset trace, and are corrected to zero offset before stacking, using the appropriate sound speed to convert from time to depth. Note that only depths at zero offset correspond to depths on a stacked section. The synthetic staircase is imaged as the next strongest coherent packet of four reflections with the same moveout, visible at higher offsets. The insets show (left) a portion of the sound speed and temperature profiles from HRP dive 123 and (right) a blow-up of the synthetic seismic shot gather marked by the rectangle. Red arrows associate the staircase reflections with the measured staircase. Also shown are relatively strong deep reflections associated with the two intrusive features (dashed arrows).

of approximately eight months. Several threads of evidence presented here strongly suggest that the feature observed toward the eastern end of seismic Line D2 is a thermohaline staircase. The CTD profile from HRP dive 125 deployed in 2001, co-located with Line D2, intersects the approximate location of the staircase imaged in 1998, but does not contain profiles with the characteristic step-like finestructure. Thus, the staircase had a lifetime of less than 3 years at this particular site. However, since this location is at the boundary of the strong staircase region identified during C-SALT (Schmitt et al., 1987), it seems most likely that the steps have simply retreated from this spot due to the varying ocean currents. It is believed that a staircase can always be found in the thermocline east of the Caribbean, since the strong vertical salinity gradients are maintained by the advection of both the salinity maximum water and salinity minimum water into the region by the general circulation.

\subsection{Weak turbulence}

Thermohaline staircases are characterized by very low levels of viscous dissipation rate of turbulent kinetic energy $(\epsilon)$.
During the C-SALT experiment, dissipation rate measured by microstructure measurements, averaged across the entire staircase, was close to the noise level of the measurements, or about $\sim 10^{-10} \mathrm{~W} \mathrm{~kg}^{-1}$ (Gregg and Sanford, 1987). Although $\epsilon$ in a staircase is very low, for the C-SALT staircase, it was found to be eight times larger than predicted for $\epsilon$ due only to the presence of internal waves (Gregg, 1989). This is likely caused by additional dissipation associated with the buoyancy flux produced by salt fingers in the interfaces. The dissipation rate from internal waves can be inferred by the finescale parameterization that employs 10-m shear measurements (Gregg, 1989)

$\epsilon_{\mathrm{IW}}=7 \times 10^{-10}\left\langle\frac{N^{2}}{N_{0}^{2}}\right\rangle\left\langle\frac{S_{10}^{4}}{S_{\mathrm{GM}}^{4}}\right\rangle$

Here $S_{\mathrm{GM}}$ and $S_{10}$ are the Garrett-Munk (GM, Garrett and Munk, 1972) and observed, respectively, shear including all vertical wavelengths greater than $10 \mathrm{~m}, N_{0}=5.2 \times 10^{-3} \mathrm{~s}^{-1}$ is the reference buoyancy frequency, $N$ is the measured buoyancy frequency, and $\langle$.$\rangle indicates an average over space$ and time. 


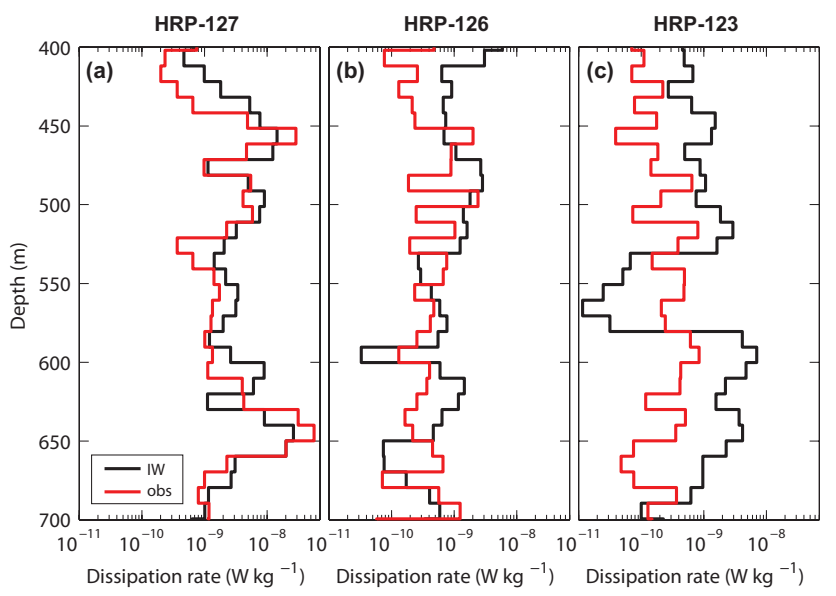

Fig. 10. Profiles of dissipation rate of turbulent kinetic energy (black) inferred using finescale internal-wave parameterization using Eq. (1) (Gregg, 1989), and (red) measured by the microstructure shear-probes for HRP dives (a) 127 (b) 126 and (c) 123.

We apply Eq. (1) to the HRP finescale velocity profiles in and outside of the staircase to show that internal-wave induced $\epsilon_{\mathrm{IW}}$ is anomalously low. We then compare $\epsilon_{\mathrm{IW}}$ to the observed dissipation rate, $\epsilon_{\mathrm{obs}}$, measured by the microstructure sensors on HRP to show that $\epsilon_{\mathrm{obs}}>\epsilon_{\mathrm{IW}}$ in the staircase, consistent with Gregg and Sanford (1987). Finally, from an independent method, using spectral analysis of seismic data, we show that spectral signature of reflectors in the staircase is consistent with low $\epsilon_{\mathrm{IW}}$.

Profiles of $\epsilon_{\mathrm{obs}}$ and $\epsilon_{\mathrm{IW}}$ for HRP dives 123, 126 and 127 are contrasted in Fig. 10. Dive 123 is in the thermohaline staircase whereas the other two dives are outside, with dive 127 located closer to the shelf break. In calculating $\epsilon_{\mathrm{IW}}$, we follow Gregg (1989) and obtain finescale shear components from linear fits over $10 \mathrm{~m}$ to the raw data and multiply by 2.11 to account for the attenuation of the first-difference filter. We average the $0.5-\mathrm{m}$ vertical resolution observed dissipation rates to $10 \mathrm{~m}$, to be consistent with $\epsilon_{\mathrm{IW}}$. Outside the staircase, at dive 127 , the dissipation rate is significantly more energetic, possibly explaining the absence of the staircase despite the low density ratio. At the depth range corresponding to the staircase, $\epsilon_{\text {IW }}$ at dive 123 is suppressed by two orders of magnitude. Observed dissipation does not show this feature, likely owing to enhanced turbulence as a result of salt fingering. It should also be noted that assumptions in the finescale parameterization and data processing of microstructure data are questionable in conditions favoring double diffusion. The agreement between the observed and predicted dissipation rate for dive 127 is remarkable. Averaged between 400$700 \mathrm{~m}$ depth for dive $127, \epsilon_{\mathrm{IW}}=5.5 \times 10^{-9} \mathrm{~W} \mathrm{~kg}^{-1}$, identical to $\epsilon_{\mathrm{obs}}=6.3 \times 10^{-9} \mathrm{~W} \mathrm{~kg}^{-1}$ within the measurement uncertainties. Dissipation rates are less at the location of dive 126 further east with $\epsilon_{\mathrm{obs}}=6 \times 10^{-10} \mathrm{~W} \mathrm{~kg}^{-1}$, in good agreement with $\epsilon_{\mathrm{IW}}=9 \times 10^{-10} \mathrm{~W} \mathrm{~kg}^{-1}$. For dive $123, \epsilon_{\mathrm{obs}}=$
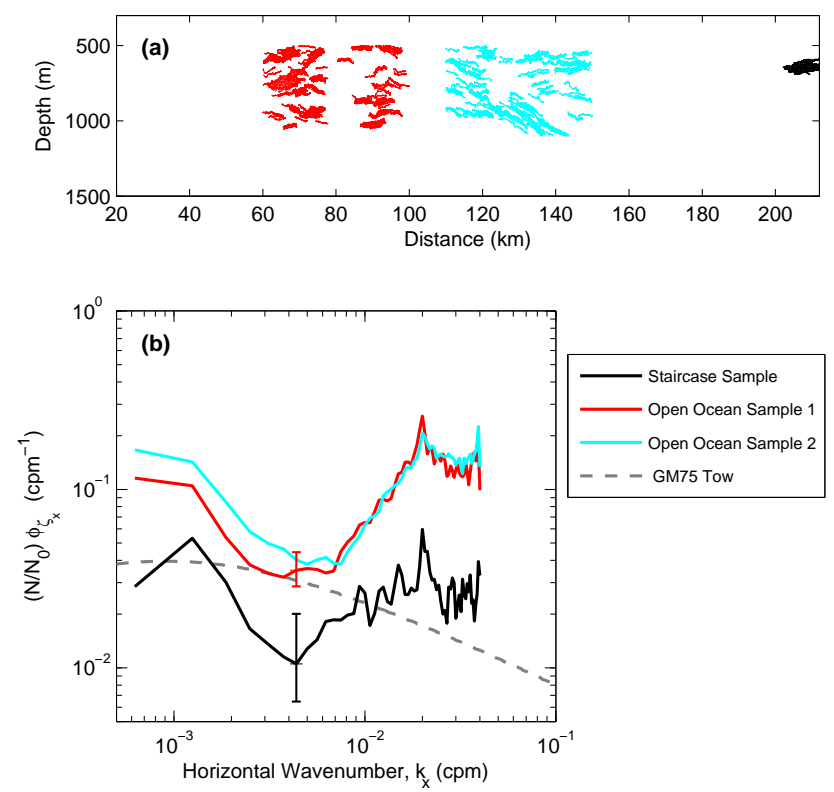

Fig. 11. (a) Reflections digitized for spectral analysis for ensembles in the staircase (black), and open ocean samples 1 (red) and 2 (cyan). (b) Ensemble-averaged slope spectra of selected horizons in the vicinity of the thermohaline staircase (black) and in the open ocean (red and cyan). All spectra are scaled by the average buoyancy frequency within the depth span of the horizons. Dashed line shows the slope spectrum inferred from GM75 tow spectrum (Katz and Briscoe, 1979) representing the average background internal wave energy for the average buoyancy frequency $(N=1.9 \mathrm{cph})$. The $95 \%$ confidence intervals are indicated for 160 and 25 degrees of freedom, respectively, for the open ocean and staircase spectra, assuming that every 6th reflector is de-correlated vertically (Krahmann et al., 2008). The energy level in the staircase is anomalously low whereas those derived from other horizons scale to a level above the GM75 spectrum.

$2.9 \times 10^{-10} \mathrm{~W} \mathrm{~kg}^{-1}$, comparable to that in the C-SALT staircase (Gregg and Sanford, 1987).

The $\epsilon_{\text {IW }}$ profile of dive 123 also shows that the internal wave field is significantly less energetic than the GM field. When averaged in the depth range of well-defined steps, $\left\langle\frac{S_{10}^{4}}{S_{\mathrm{GM}}^{4}}\right\rangle$ is about 0.8. This is in agreement with Gregg (1989) who found $\left\langle\frac{s_{10}^{4}}{S_{\mathrm{GM}}^{4}}\right\rangle$ of about 0.6 for the C-SALT staircase. Resulting dissipation rates are very low accordingly. Consistent with our measurements and C-SALT results, we infer a low internal wave signature in the seismic transect in the vicinity of the staircase.

Spectral analysis of reflections from the western part of the line, between $50-150 \mathrm{~km}$ is shown in Fig. 11. Following Holbrook and Fer (2005), we compare ensembleaveraged horizontal wavenumber spectra of reflection displacement to the Garrett-Munk tow spectrum (GM75, Garrett and Munk, 1975), as described in Katz and Briscoe (1979). 
Here, however, we present the slope spectra as described in Sect. 2.4. The GM75 spectrum is scaled by the survey mean $N=1.9( \pm 0.28)$ cph between $400-1000 \mathrm{~m}$ depth, the typical range of the selected reflections. In total 476 and 477 segments of $1600 \mathrm{~m}$ length were picked in the open ocean along Line D2, between $60-100 \mathrm{~km}$ and $110-150 \mathrm{~km}$, respectively. The average spectrum from each set of ensembles, representative of the open ocean agree with the GM75 level within $95 \%$ confidence between $2 \times 10^{-3}$ and $7 \times 10^{-3} \mathrm{cpm}$ (500-125 m wavelengths). At lower wavenumbers the GM75 curve whitens whereas the observed spectra show a slope comparable to the $k_{x}^{-0.5}$ slope of the highwavenumber portion of the GM75 spectrum. Average slope from the open ocean samples between $500-125 \mathrm{~m}$ wavelengths is $-0.6 \pm 0.1$. This is consistent with Klymak and Moum (2007) who suggested that $k_{x}^{-0.5}$ is a good model for the internal-wave subrange at low horizontal wavenumbers. The relatively elevated spectral level at $1 \mathrm{~km}$ wavelength can be attributed to the Aves Ridge and variable local bathymetry.

Within the thermohaline staircase, 75 segments of $1600 \mathrm{~m}$ length are available for spectral analysis. The ensembleaveraged spectrum in the thermohaline staircase, however, contains lower variance, significant at $95 \%$ confidence, relative to the samples from the open ocean. The slope at wavenumbers less than $5 \times 10^{-3} \mathrm{cpm}$ is $-0.7 \pm 0.2$, slightly steeper than the open ocean spectra. In general, energy in the staircase does not compare well with and is significantly less energetic than the GM75 tow spectrum at wavelengths less than $1 \mathrm{~km}$. The spectral level at scales larger than $1 \mathrm{~km}$ suggest a background internal wave activity that might lead to weak turbulent fluxes; however, the existence of the regular structure in the staircase shows that double-diffusive fluxes must dominate.

Klymak and Moum (2007) show that the turbulence subrange of isopycnal slope spectra extends to surprisingly large horizontal wavelengths $(>100 \mathrm{~m})$ and can be distinguished with a $k_{x}^{1 / 3}$ slope. In our data set, the slope spectra from the reflections are contaminated by noise at high wavenumbers, dominated by the peak at $50 \mathrm{~m}$ wavelength due to shot spacing. Following the kink at $7 \times 10^{-3} \mathrm{cpm}$ the open ocean spectra show a $k_{x}^{1.5}$ slope until $50 \mathrm{~m}$ wavelength as a result of noise, and cannot be interpreted in terms of turbulence subrange. Purposefully designed seismic reflection profiling sampling can be used to infer dissipation rates in the ocean, however, this is beyond the scope of our paper.

\section{Conclusions}

Our study indicates that the seismic reflection method is able to image the step-like structure of a thermohaline staircase. We present a seismic line from the Lesser Antilles which contains closely spaced reflections, horizontally coherent over $4 \mathrm{~km}$, appearing clearly as high-amplitude interfaces separated by increasing distance with depth, from 19 to $25 \mathrm{~m}$. The general area of the western tropical North Atlantic has been known to harbor staircases for at least the last 40 years. Synthetic modeling using the density and sound speed structure from a CTD containing the step-like structure of a thermohaline staircase indicates that the seismic reflection method is able to image it correctly and serves as a validation for our observations. Reflections from the synthetic staircase are closely spaced with amplitudes comparable to those that arrive at the same times in the seismic data. A comparison of reflection coefficients from a strong thermohaline staircase sampled during the C-SALT experiment with those calculated from the seismic data indicates that they have similar spacing and magnitudes, i.e., the seismic line imaged a strong staircase.

Spectral analysis of reflections indicates that the inferred internal wave level in the vicinity of the staircase is anomalously low, relative to adjacent measurements. A finescale parameterization applied to independent measurements of velocity profiles in and outside of the staircase confirms the weak internal wave field and very low internal wave induced dissipation within the staircase. Microstructure measurements show that the observed dissipation rates in the staircase are one order of magnitude less than those outside the staircase. Whether weak internal waves allow the formation of the staircase, or the double-diffusive convection of the staircase suppresses the internal waves via the mechanism of Ruddick (1985), is not known at this time.

A CTD profile taken in 2001 in the location of the staircase imaged in 1998 indicates that the layers are not permanent and have a lifetime of less than three years in this immediate area. Evidence gathered from a combination of seismic observations, modeling, finescale hydrography and currents, and microstructure measurements supports the notion that legacy seismic data can be used to map thermohaline staircases. With sufficiently tuned modern data, layer thickness and temperature jumps across interfaces can be inferred from the impedance contrasts and allow for diffusive flux estimates from widely-used parameterizations. Such structural and physical observations can then be compared for a greater understanding of finestructure and mixing processes in the global ocean.

Acknowledgements. This research was supported by NSF grant OCE-0221366 and ONR grant ONR-N000140410585 to Holbrook, NSF grant OCE-0647573 to Schmitt and the University of Wyoming Graduate School Women and Minority Fellowship to Nandi. We thank B. Ruddick, K. Sheen and an anonymous reviewer for their helpful comments and suggestions.

Edited by: K. J. Heywood 


\section{References}

Bangs, N.: Ewing Cruise EW9803, 15 March-6 April 1998, Structure tectonics and sediment flow through the Lesser Antilles Subduction Zone, Tech. Rep., Institute og Geophysics, University of Texas, 1998.

Biescas, B., Sallarès, V., Pelegri, J. L., Machin, F., Carbonell, R., Buffett, G., Dañobeitia, J. J., and Calahorrano, A.: Imaging Meddy finestructure using multichannel seismic data, Geophys. Res. Lett., 35, L11609, doi:10.1029/2008GL033971, 2008.

Fer, I. and Holbrook, W. S.: Seismic reflection methods for study of the water column, in: Encylopedia of Ocean Sciences, 2nd Edn., edited by: Steele, J. H., Turekian, K. K., and Thorpe, S. A., Academic Press, Oxford, 2008.

Fortin, W. F. J. and Holbrook, W. S.: Sound speed requirements for optimal imaging of seismic oceanography data, Geophys. Res. Lett., 36, L00D01, doi:10.1029/2009g1038991, 2009.

Garrett, C. J. and Munk, W. H.: Space-time scales of internal waves, Geophys. Fluid Dyn., 3, 225-264, 1972.

Garrett, C. J. and Munk, W. H.: Space-time scales of internal waves: A progress report, J. Geophys. Res., 80, 291-297, 1975.

Gregg, M. C.: Scaling turbulent dissipation in the thermocline, J. Geophys. Res., 94, 9686-9698, 1989.

Gregg, M. C. and Sanford, T. B.: Shear and turbulence in thermohaline staircases, Deep-Sea Res. A, 34, 1689-1696, 1987.

Holbrook, W., Páramo, P., Pearse, S., and Schmitt, R.: Thermohaline fine structure in an oceanographic front from seismic reflection profiling, Science, 301, 821-824, 2003.

Holbrook, W. S. and Fer, I.: Ocean internal wave spectra inferred from seismic reflection transects, Geophys. Res. Lett., 32, L15604, doi:10.1029/2005GL023733, 2005.

Holbrook, W. S., Fer, I., and Schmitt, R. W.: Images of internal tides near the Norwegian continental slope, Geophys. Res. Lett., 36, L00D10, doi:10.1029/2009GL038909, 2009.

Katz, E. J. and Briscoe, M. G.: Vertical coherence of the internal wave field from towed sensors, J. Phys. Oceanogr., 9, 518-530, 1979.

Kelley, D. E.: Effective diffusivities within oceaninc thermohaline staircases, J. Geophys. Res., 89, 10484-10488, 1984.

Kelley, D. E., Fernando, H. J. S., Gargett, A. E., Tanny, J., and Özsoy, E.: The diffusive regime of double-diffusive convection, Prog. Oceanogr., 56, 461-481, 2003.

Klymak, J. M. and Moum, J. N.: Oceanic isopycnal slope spectra. Part II: Turbulence, J. Phys. Oceanogr., 37, 1232-1245, 2007.

Krahmann, G., Brandt, P., Klaeschen, D., and Reston, T.: Middepth internal wave energy off the Iberian Peninsula estimated from seismic reflection data, J. Geophys. Res., 113, C12016, doi: 10.1029/2007JC004678, 2008.

Mazeika, P. A.: Subsurface mixed layers in the northwest tropical Atlantic, J. Phys. Oceanogr., 4, 446-453, 1974.

Nakamura, Y., Noguchi, T., Tsuji, T., Itoh, S., Niino, H., and Matsuoka, T.: Simultaneous seismic reflection and physical oceanographic observations of oceanic fine structure in the Kuroshio extension front, Geophys. Res. Lett., 33, L23605, doi:10.1029/ 2006GL027437, 2006.

Nandi, P., Holbrook, W. S., Pearse, S., Paramo, P., and Schmitt, R. W.: Seismic reflection imaging of water mass boundaries in the Norwegian Sea, Geophys. Res. Lett., 31, L23311, doi:10. 1029/2004GL021325, 2004.
Pinheiro, L. M., Song, H., Ruddick, B., Dubert, J., Ambar, I., Mustafa, K., and Bezerra, R.: Detailed 2-D imaging of the Mediterranean outflow and meddies off W Iberia from multichannel seismic data, J. Marine Syst., 79, 89-100, 2010.

Polzin, K. L. and Montgomery, E. T.: Microstructure Profiling with the High Resolution Profiler, Tech. Rep., Woods Hole Oceanographic Institution, 1998.

Ruddick, B. R.: Momentum transport in thermohaline staircases, J. Geophys. Res., 90, 895-902, 1985.

Ruddick, B. R., Song, H., Dong, C., and Pinheiro, L.: Water column seismic images as maps of temperature gradient, Oceanography, 22, 192-205, 2009.

Sallarès, V., Biescas, B., Buffett, G., Carbonell, R., Dañobeitia, J. J., and Pelegri, J. L.: Relative contribution of temperature and salinity to ocean acoustic reflectivity, Geophys. Res. Lett., 36, L00D06, doi:10.1029/2009g1040187, 2009.

Schmitt, R. W.: Form of the temperature-salinity relationship in the central water - evidence for double-diffusive mixing, J. Phys. Oceanogr., 11, 1015-1026, 1981.

Schmitt, R. W.: On the density ratio balance in the central water, J. Phys. Oceanogr., 20, 900-906, 1990.

Schmitt, R. W.: Observational and laboratory insights into salt finger convection, Prog. Oceanogr., 56, 419-433, 2003.

Schmitt, R. W., Perkins, H., Boyd, J. D., and Stalcup, M. C.: CSALT - An investigation of the thermohaline staircase in the western tropical North-Atlantic, Deep-Sea Res. A, 34, 16551665, 1987.

Schmitt, R. W., Toole, J. M., Koehler, R. L., Mellinger, E. C., and Doherty, K. W.: The Development of a Fine- and Microstructure Profiler, J. Atmos. Ocean. Technol., 5, 484-500, 1988.

Schmitt, R. W., Ledwell, J. R., Montgomery, E. T., Polzin, K. L., and Toole, J. M.: Enhanced diapycnal mixing by salt fingers in the thermocline of the tropical Atlantic, Science, 308, 685-688, 2005.

Sheriff, R. E. and Geldart, L. P.: Exploration Seismology, 2nd Edn., Cambridge University Press, 592 pp., 1995.

St. Laurent, L. C. and Schmitt, R. W.: The contribution of salt fingers to vertical mixing in the North Atlantic tracer release experiment, J. Phys. Oceanogr., 29, 1404-1424, 1999.

Stern, M. E.: The "salt-fountain" and thermohaline convection, Tellus A, 12, 172-175, 1960.

Sundfjord, A., Fer, I., Kasajima, Y., and Svendsen, H.: Observations of turbulent mixing and hydrography in the marginal ice zone of the Barents Sea, J. Geophys. Res., 112, C05008, doi:10.1029/ 2006JC003524, 2007.

Turner, J. S.: Buoyancy Effects in Fluids, Cambridge University Press, New York, 1973.

Warner, M.: Absolute reflection coefficients from deep seismic reflections, Tectonophysics, 173, 15-23, 1990.

Widess, M.: How thin is a thin bed?, Geophysics, 38, 1176-1180, 1973.

Zhang, J. and Schmitt, R. W.: The impact of salt fingering on the thermohaline circulation under mixed boundary conditions, J. Phys. Oceanogr., 30, 1223-1231, 2000. 